\title{
Daily mortality and "winter type" air pollution in Athens, Greece - a time series analysis within the APHEA project
}

\author{
G Touloumi, E Samoli, K Katsouyanni
}

\begin{abstract}
Study objective - There is evidence that air pollution in Athens between 1975 and 1987 had adverse short term health effects. The short term effects of "winter type" air pollution on the daily total number of deaths are investigated for the period 1987-91 as part of the European Community multi centre APHEA project.

Design - A temporal study using aggregated data is presented. The associations of the daily time series of three pollutants, sulphur dioxide $\left(\mathrm{SO}_{2}\right)$, black smoke (BS), and carbon monoxide (CO) and the daily total number of deaths in the Athens area were assessed.

Data and methods - The average measurement from three stations was used for each pollutant. The daily number of deaths was recorded from the Athens Town Registry and the registries of the 18 municipalities contiguous to Athens. Data on the mean daily temperature $\left({ }^{\circ} \mathrm{C}\right)$ and relative humidity (\%) were also used. Poisson autoregressive models that also allowed for overdispersion were used. Seasonality, other long term patterns, temperature, humidity, day of the week, and holidays were adjusted for. Several a priori defined pollutant transformations and lags were investigated. One day measurements as well as cumulative exposure effects were assessed. Effect modification by season as well as among pollutants was tested.
\end{abstract}

Main results - Linear terms were used for all pollutants. The magnitude of the effect was greater at lags 0 for $\mathrm{CO}$ and 1 for BS and $\mathrm{SO}_{2}$ gradually declining after lag 1 . For an increase of $100 \mu \mathrm{g} / \mathrm{m}^{3}$ in $\mathrm{SO}_{2}$ and BS there were corresponding increases $(95 \% \mathrm{CI})$ of $12 \%(7 \%, 16 \%)$ and $5 \%(3 \%$, $8 \%$ ) in the daily total numbers of deaths, while for an increase of $10 \mu \mathrm{g} / \mathrm{m}^{3}$ in $\mathrm{CO}$ the increase $(95 \% \mathrm{CI})$ in the daily total number of deaths was $10 \%(5 \%, 15 \%)$. A significant interaction of the effects of $\mathrm{SO}_{2}$ with season were found. The strongest effect was observed during the winter, when higher levels of $\mathrm{SO}_{2}$ were observed. A stronger effect of $\mathrm{SO}_{2}$ on the daily total number of deaths was observed when the levels of BS were $>100 \mu \mathrm{g} / \mathrm{m}^{3}$.

Conclusions - These results strengthen the evidence of a causal association between ambient particle, $\mathrm{SO}_{2}$, or $\mathrm{CO}$ levels in the air and the daily total number of deaths and points to an important public health issue for the Athens population.

( $(\mathcal{E}$ Epidemiol Comm Health 1996;50(Supp 1):S47-S51)

Several recent papers have provided evidence that moderate or even relatively low air pollution levels such as those observed today in US and European cities where limit values are rarely exceeded, have adverse short term health effects, including effects on mortality. ${ }^{1-7}$ Athens has an important air pollution problem and previous studies concerning data from 1975-88 have indicated effects of the current levels of pollutants on the daily number of deaths. ${ }^{8-10}$ Furthermore, due to the mild climate of Athens and the hot summers there is evidence of differential effects in relation to season. ${ }^{11}$ The analysis presented here is part of the Greek participation in the APHEA project and concerns the effects on health of "winter type" pollutants (black smoke (BS), sulphur dioxide $\left(\mathrm{SO}_{2}\right)$, and carbon monoxide (CO)) during the most recent 5 year period for which data are available. It therefore assesses the role of long term changes in the air pollution mixture from 1987-91. The analytical methods used follow the common APHEA protocol and have not been applied before to the Athens data. The potential effect modification in relation to season and the interaction between pollutants is also investigated.

\section{Methods}

DESIGN

This is a temporal study using aggregated data. This type of study, although ecological, has fewer problems of confounding than other ecological designs based on geographical or other units of aggregation. Potential confounding factors must vary chronologically, while important causes of the outcome studied cannot confound the pollution-mortality association if they remain relatively constant over the study period. ${ }^{1213}$

\section{STUDY AREA}

The Athens area forms a basin surrounded by mountains on the north, east, and north west and by the sea on the south west side. The topography favours atmospheric inversions and the concentrations of pollutants measured are high even in the presence of relatively limited emissions. ${ }^{15}$ The climate is Mediterranean with wet, mild winters and long, hot and dry 
Table 1 Air pollution levels in Athens, 1987-91

\begin{tabular}{lcccc}
\hline & \multicolumn{2}{l}{ Monitoring site } & & \multirow{2}{*}{ Average } \\
\cline { 2 - 3 } & Patision & Piraeus & Ipourgio & \\
\hline Black smoke $\mu \mathrm{g} / \mathrm{m}^{3}-24 \mathrm{~h}:$ & & & & \\
Mean & 124 & $49 \cdot 1$ & 80 & $84 \cdot 4$ \\
SD & 77 & $28 \cdot 7$ & $55 \cdot 8$ & 48 \\
Median & 106 & 44 & 65 & $73 \cdot 3$ \\
Minimum & 10 & 6 & 8 & 333 \\
Maximum & 415 & 285 & 661 & \\
\% missing & $2 \cdot 1$ & $10 \cdot 5$ & 2 & \\
& & & & \\
& Patision & Piraeus & Smirni & \\
SO $\mu \mathrm{gg} / \mathrm{m}^{3}-24 \mathrm{~h}:$ & & & & \\
Mean & 75 & $54 \cdot 6$ & $23 \cdot 6$ & $51 \cdot 3$ \\
SD & 46 & $37 \cdot 3$ & $20 \cdot 4$ & $29 \cdot 8$ \\
Median & 65 & 47 & 19 & 45 \\
Minimum & 6 & 7 & 6 & 6 \\
Maximum & 359 & 253 & 264 & 361 \\
\% missing & $2 \cdot 1$ & $9 \cdot 1$ & $7 \cdot 7$ & \\
CO mg/m ${ }^{3}-8 \mathrm{~h}:$ & & & & \\
Mean & 11 & $6 \cdot 1$ & $2 \cdot 7$ & $6 \cdot 6$ \\
SD & $4 \cdot 7$ & $2 \cdot 5$ & $2 \cdot 1$ & $2 \cdot 6$ \\
Median & 10 & $5 \cdot 9$ & 2 & $6 \cdot 1$ \\
Minimum & 2 & $1 \cdot 1$ & $0 \cdot 1$ & $1 \cdot 4$ \\
Maximum & 35 & $18 \cdot 5$ & $16 \cdot 6$ & $24 \cdot 9$ \\
\% missing & $1 \cdot 4$ & $9 \cdot 5$ & $10 \cdot 4$ & \\
\hline
\end{tabular}

summers. ${ }^{810}$ The population in the Athens region is over 3000000 inhabitants $^{16}$ and the built up area about $350 \mathrm{~km}^{2} .^{15}$

\section{AIR POLLUTION DATA}

The air pollution measurements were provided by the Monitoring Network operated by the Ministry of Environment, Planning and Public Works. $\mathrm{SO}_{2}$ is measured by the pulsed fluorescence method, BS by the OECD method, and $\mathrm{CO}$ by the infrared, non-dispersive method. ${ }^{15}$ According to the criteria of the APHEA project, for completeness of the pollution time series data the average daily measurements of three stations were used for each pollutant as follows: for BS (24 hour level in $\mu \mathrm{g} / \mathrm{m}^{3}$ ) Patision, Ipourgio, and Piraeus; for $\mathrm{SO}_{2}(24$ hour levels in $\mu \mathrm{g} /$ $\mathrm{m}^{3}$ ) Patision, Piraeus, and Smyrni; for CO (maximum 8 hour moving average in $\mathrm{mg} / \mathrm{m}^{3}$ ) Patision, Pireaus, and Smyrni. The stations cover the study area and may be thought of as representing the population exposure. ${ }^{10}$ However, it must be noted that the two stations (Patission and Ipourgio) giving BS measurements are closer together than Patision and Smyrni used for $\mathrm{SO}_{2}$ and $\mathrm{CO}$ determinations and this may result in somewhat different representation of the population exposure for the three pollutants. The Pearson correlations between the daily measurements at different stations range from 0.4 to 0.7 . In table 1 , descriptive statistics for measurements in each station as well as for the average of all stations are shown for the study period. During this period BS exceeded the WHO air quality guideline ${ }^{17}$ on $42 \%$ of the days, $\mathrm{SO}_{2}$ on $12 \%$ of the days, and $\mathrm{CO}$ on $54 \%$ of the days in the centre of Athens (Patision) where the highest levels of each pollutant were observed. Missing values in each station were completed as described previously. ${ }^{13}$ Figure 1 shows the time series of the three pollutants. A clear seasonal pattern is evident, with higher levels of all three pollutants during the late autumn - early winter.
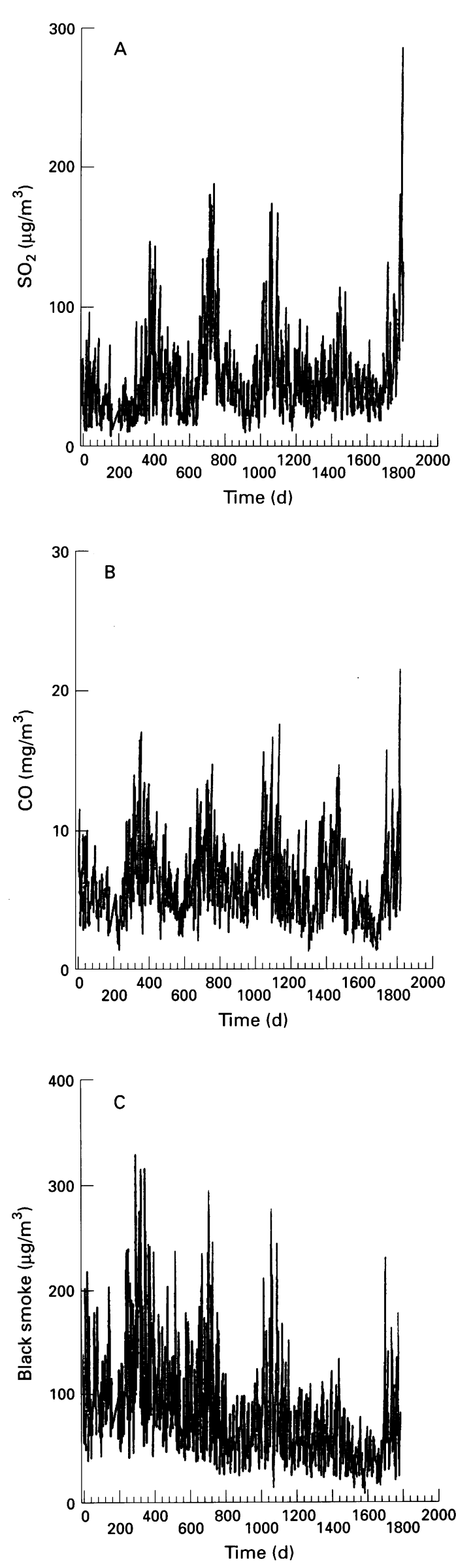

Figure 1 Time series of daily air pollutant levels in Athens, from Fanuary 1, 1987 to December 31, 1991. (Average of three monitoring stations). 


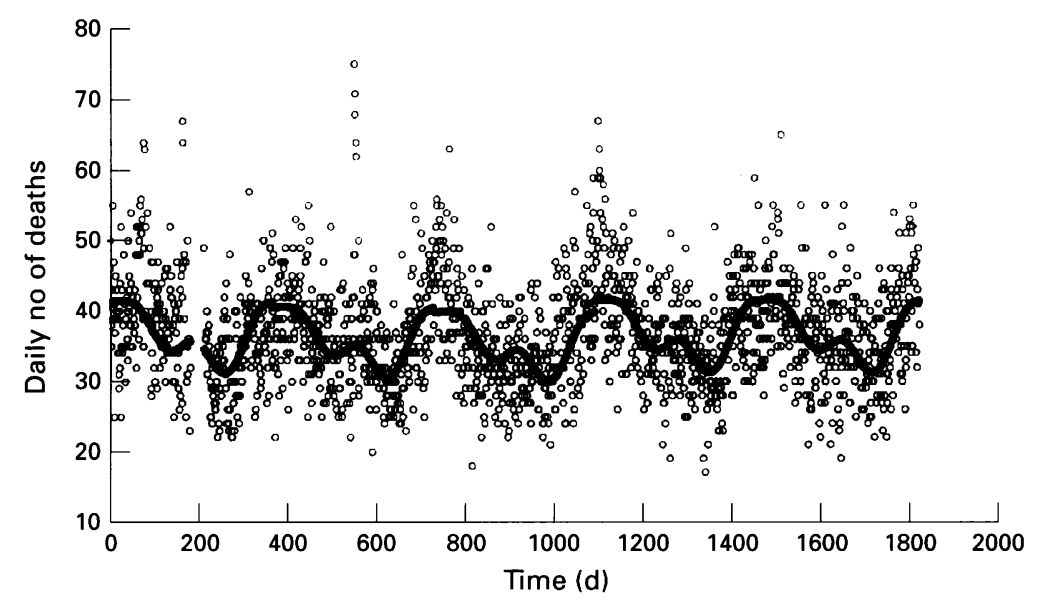

Figure 2 Time series of observed and predicted (after adjusting for seasonal pattern and long term trend) daily total number of deaths in the Athens area from fanuary 1, 1987 to December 31, 1991. investigated. The significant contribution of each variable on model fitness was assessed by the appropriate $\mathrm{F}$ test. ${ }^{13}$ After the "core" model variables had been chosen, residuals of mortality were plotted against time to check if cyclical and long term patterns had been efficiently removed. The next stage of the analysis included the alternative introduction of pollutants, after appropriate transformations (linear, log, or square root) and lags, in the model. It had been decided to test lags 0 to 2 for one day measurements and the average of two to four days for the evaluation of the effects of prolonged exposure. At the final stage, Poisson autoregressive models allowing also for overdispersion $^{19}$ were applied. Effect modification by season was tested by introducing a dummy variable for season (October-December and January-March defined the winter period) and its interaction term with the pollutant included into the model. Similarly, interactions among pollutants were tested. More specifically, effect modification of $\mathrm{SO}_{2}$ by the levels of BS (below or over $100 \mu \mathrm{g} / \mathrm{m}^{3}$ ) and vice versa for BS by levels of $\mathrm{SO}_{2}$ were investigated.

The daily number of deaths for the period $1 /$ $1 / 1987$ to $30 / 12 / 1991$ (a total of 1826 days) was recorded from the Athens Town Registry and the registries of all towns contiguous to Athens (19 town registries). In July 1987, the total daily number of deaths increased by more than $100 \%$ due to a heat wave and this month was excluded from all further analyses as a climate "outlier". After this exclusion, the mean (SD) daily number of deaths during the study period was $37 \cdot 2(8 \cdot 0)$.

\section{METEOROLOGICAL DATA}

The mean daily temperature $\left({ }^{\circ} \mathrm{C}\right)$ and mean daily relative humidity (\%) from the Institute of Meteorology and Physics of the Atmospheric Environment ${ }^{18}$ were used to control for meteorological potential confounding effects. The mean (SD) temperature for the whole study period was $17 \cdot 6^{\circ} \mathrm{C}(7 \cdot 2)$ and the mean relative humidity $61 \cdot 7 \%(12 \cdot 5)$.

\section{STATISTICAL ANALYSIS}

The procedure followed adhered to the APHEA group decisions in order to ensure comparability of results as described previously. ${ }^{1314}$

Initially the "core" model was constructed investigating the association of the daily number of deaths (log transformed) with all potential confounders.

First seasonality and other long term cyclical patterns were controlled for using sinusoidal terms. The order of the sinusoidal curves included was decided on the basis of statistical significance. ${ }^{13}$ To adjust for long term trends, dummy variables for years and linear and quadratic terms for trend were alternatively examined. After seasonal and long term patterns were removed from the mortality series, the short term effects of weather on mortality were examined on the basis of model fit using different functions of temperature and humidity. In addition, the effect of the day of the week (six dummy variables) and holidays were also

\section{Results}

"CORE" MODEL

To adjust for seasonal patterns, cosine and sine months were included in the model. Sinusoidal terms with a period of two years were also tested but were not included in the final model as they did not contribute significantly to its fit.

Long term trends were controlled for by the introduction of dummy variables for each year. Inclusion of one linear term for long term trend (with values of 1 to 1826) resulted in nonsignificant change in the model fit, indicating that in our data there was no systematic increasing or decreasing trend in the number of deaths over the study period.

Figure 2 shows the plot of the raw mortality data against time. A strong seasonal pattern is evident with higher daily number of deaths during the winter months. In the figure, the predicted mortality, allowing for seasonal and long term patterns, is also superimposed. Apart from the annual cycles, another less pronounced peak is observed during the summer months (July-August).

The $U$ shaped relationship of temperature and mortality (higher numbers of deaths during very cold or very hot days, but with a steeper slope at higher temperatures) was addressed using a double quadratic function of temperature. Two complementary variables "hot" and "cold", with a changing point at $22^{\circ} \mathrm{C}$, were constructed for this purpose and their squared values were introduced in the model. ${ }^{10}$ Relative humidity was included in the core model as a linear term, although it was not statistically significant at the nominal level. The temperature and humidity terms chosen were lagged by one day, after testing lags up to 2 . the week, which contributed marginally to the model fit $(p<0 \cdot 10)$ were included in the "core" model, while the variable for holidays was disterms with periods of 1 year, 6 months, and 4 Finally, dummy variables indicating days of 
Table 2 Parameter estimates for the "core" model variables from Poisson autoregressive model

\begin{tabular}{|c|c|c|c|}
\hline Variable & $\begin{array}{l}\text { Regression } \\
\text { coefficient }\end{array}$ & $\begin{array}{l}\text { Standard } \\
\text { error }\end{array}$ & $(95 \% C I)$ \\
\hline Cold $^{2 *} \ddagger$ & 0.0003 & $0 \cdot 00007$ & $(0 \cdot 00016,0.00044)$ \\
\hline $\operatorname{Hot}^{2}+\ddagger^{2}$ & 0.0053 & $0 \cdot 00044$ & $(0.00443,0.00617)$ \\
\hline Humidity (\%)‡ & 0.00037 & 0.00046 & $(-0.00053,0.00126)$ \\
\hline Year 1987 & -0.00889 & 0.01315 & $(-0.03468,0.0169)$ \\
\hline Year 1988 & -0.02616 & 0.01311 & $(-0.05187,-0.00044)$ \\
\hline Year 1989 & -0.02868 & 0.01326 & $(-0.0547,-0.00267)$ \\
\hline Year 1990 & 0.00247 & 0.01312 & $(-0.02326,0.0282)$ \\
\hline Year 1991 & Reference category & & \\
\hline Monday & Reference category & & \\
\hline Tuesday & -0.02082 & 0.01519 & $(-0.05062,0.00898)$ \\
\hline Wednesday & -0.01176 & 0.0152 & $(-0.04157,0.01805)$ \\
\hline Thursday & -0.01989 & 0.01523 & $(-0.04976,0.00998)$ \\
\hline Friday & -0.00877 & 0.01518 & $(-0.03854,0.02101)$ \\
\hline Saturday & -0.05077 & 0.01534 & $(-0.08086,-0.02068)$ \\
\hline Sunday & -0.02497 & 0.01522 & $(-0.05481,0.00488)$ \\
\hline $\mathrm{Cos}^{\mathrm{a}}$ & 0.1225 & 0.0109 & $(0 \cdot 10112,0 \cdot 14388)$ \\
\hline $\operatorname{Sin}^{\mathrm{a}}$ & $0 \cdot 08591$ & 0.00684 & $(0.07249,0.09934)$ \\
\hline $\operatorname{Cos} 2^{b}$ & 0.01451 & 0.00661 & $(0.00154,0.02747)$ \\
\hline $\operatorname{Sin} 2^{b}$ & -0.03047 & 0.00673 & $(-0.04366,-0.01728)$ \\
\hline $\cos 3^{c}$ & -0.01377 & 0.00587 & $(-0.02528,-0.00227)$ \\
\hline $\operatorname{Sin} 3^{c}$ & 0.00211 & 0.00618 & $(-0.01002,0.01424)$ \\
\hline RI & $0 \cdot 11011$ & 0.02365 & $(0.06372,0.1565)$ \\
\hline R2 & $0 \cdot 12049$ & 0.02364 & $(0.07413,0.16684)$ \\
\hline
\end{tabular}

* Cold: $22-$ temperature, if temperature $\leq 22^{\circ} \mathrm{C}, 0$ otherwise

thot: temperature -22 , if temperature $>22^{\circ} \mathrm{C}, 0$ otherwise

$\ddagger$ lagged by one day

a cos: $\cos \left(2 \pi / 365^{*} \mathrm{t}_{\mathrm{i}}\right)$; $\sin : \sin \left(2 \pi / 365^{*} \mathrm{t}_{\mathrm{i}}\right), \mathrm{i}=1$ to 365

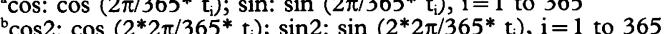

'cos $3: \cos \left(3^{*} 2 \pi / 365^{*} t_{i}\right) ; \sin 3: \sin \left(3^{*} 2 \pi / 365^{*} t_{i}\right), i=1$ to 365

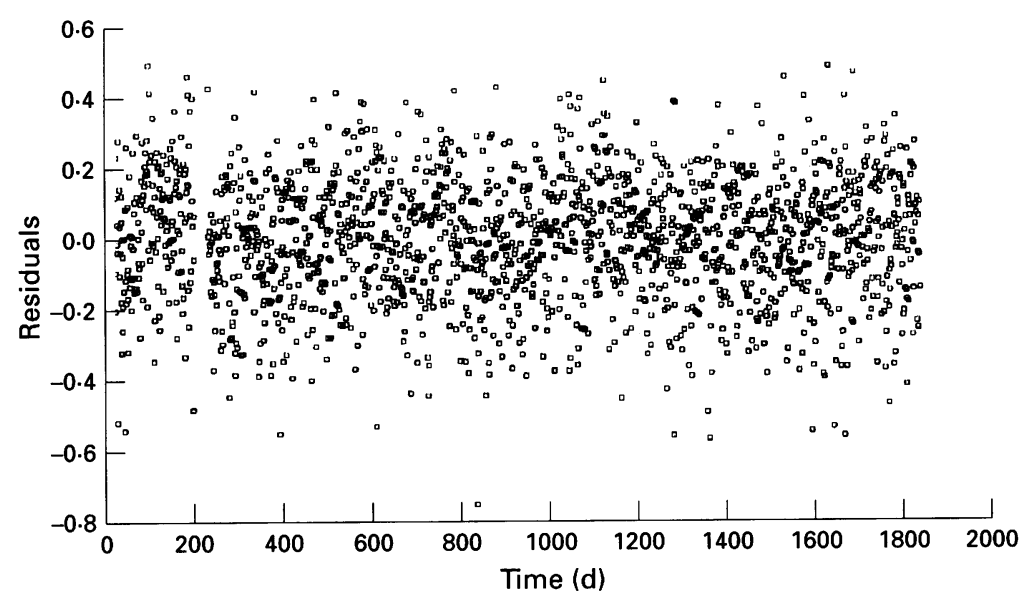

Figure 3 Time plot of residuals of the daily total number of deaths from a model including all potential confounding variables.

Table 3 Parameter estimates for pollution variables from autoregression Poisson models

\begin{tabular}{|c|c|c|c|}
\hline Pollutant & $\begin{array}{l}\text { Regression } \\
\text { coefficient }\end{array}$ & $\begin{array}{l}\text { Standard } \\
\text { error }\end{array}$ & $(95 \% C I)$ \\
\hline \multicolumn{4}{|l|}{$1 d$ exposure } \\
\hline $\begin{array}{l}\mathrm{SO}_{2}\left(\mu \mathrm{g} / \mathrm{m}^{3}, \text { lag } 1\right) \\
\text { Black smoke }\left(\mu \mathrm{g} / \mathrm{m}^{3}, \operatorname{lag} 1\right)\end{array}$ & $\begin{array}{l}0.00110 \\
0.00048\end{array}$ & $\begin{array}{l}0.00016 \\
0.00011\end{array}$ & $\begin{array}{l}(0 \cdot 00078,0 \cdot 00141) \\
(0.00027,0.000692)\end{array}$ \\
\hline $\mathrm{CO}\left(\mathrm{mg} / \mathrm{m}^{3}\right.$, lag0 $)$ & 0.00650 & 0.00203 & $(0.00249,0 \cdot 01046)$ \\
\hline \multicolumn{4}{|l|}{ Cumulative exposure } \\
\hline $\mathrm{SO}_{2}\left(\mu \mathrm{g} / \mathrm{m}^{3}\right.$ lags0-3) & 0.00155 & 0.00021 & $(0 \cdot 00144,0 \cdot 00196)$ \\
\hline Black smoke $\left(\mu \mathrm{g} / \mathrm{m}^{3}\right.$, lag0-1) & 0.00049 & 0.00012 & $(0 \cdot 00026,0 \cdot 00072)$ \\
\hline $\mathrm{CO}\left(\mathrm{mg} / \mathrm{m}^{3}\right.$, lags $\left.0-1\right)$ & 0.00906 & 0.00229 & $(0 \cdot 00457,0 \cdot 01354)$ \\
\hline
\end{tabular}

carded since it did not improve the model fit. In table 2 the variables included in the core model, their partial regression coefficients, standard errors, and $95 \%$ confidence intervals from a Poisson autoregressive model are shown.

Figure 3 shows the plot of the residuals against time after the "core" model has been fitted. There is no evidence of remaining long term trends or cyclical patterns.
Table 4 Estimated relative risk (RR) of dying corresponding to increased air pollutants levels from Poisson autoregressive models including 1 day pollutant measurements

\begin{tabular}{lll}
\hline Increase in pollutant & Corresponding $R R$ & $95 \% \mathrm{CI}$ \\
\hline $100 \mu \mathrm{g} / \mathrm{m}^{3} \mathrm{SO}_{2}$ & $1 \cdot 12$ & $(1 \cdot 07,1 \cdot 16)$ \\
$87.2 \mu \mathrm{g} / \mathrm{m}^{3} \mathrm{SO}_{2}{ }^{*}$ & $1 \cdot 10$ & $(1 \cdot 07,1 \cdot 13)$ \\
$100 \mu \mathrm{g} / \mathrm{m}^{3}$ black smoke & 1.05 & $(1 \cdot 03,1 \cdot 08)$ \\
$150 \mu \mathrm{g} / \mathrm{m}^{3}$ black smoke* & 1.08 & $(1 \cdot 04,1 \cdot 11)$ \\
$10 \mathrm{mg} / \mathrm{m}^{3} \mathrm{CO}$ & $1 \cdot 10$ & $(1 \cdot 05,1 \cdot 15)$ \\
$7.6 \mathrm{mg} / \mathrm{m}^{3} \mathrm{CO}^{*}$ & 1.05 & $(1 \cdot 02,1 \cdot 08)$ \\
\hline
\end{tabular}

* Corresponding to a change from the 5 th to the 95 th centile of the pollutant's distribution.

\section{AIR POLLUTANTS}

For all three pollutants linear terms were chosen. One day measurements were lagged by 1 for $\mathrm{SO}_{2}$ and $\mathrm{BS}$, since the magnitude of the regression coefficients at this lag were substantially higher compared with those at lag 0 , while for $\mathrm{CO}$ the coefficient at lag 0 was slightly higher than that at lag 1 and was therefore chosen. When the pollutants' values were lagged by more than 1 day their regression coefficients became progressively smaller. The average of 4 days for $\mathrm{SO}_{2}$ and of 2 days for $\mathrm{BS}$ and $\mathrm{CO}$ were chosen to indicate cumulative pollutants exposure. In table 3 the results of the final Poisson autoregressive models for each pollutant are shown. In table 4 the relative risks of dying on a given day when pollutant levels were higher by $100 \mu \mathrm{g} / \mathrm{m}^{3}$ for $\mathrm{SO}_{2}$ and $\mathrm{BS}$ or $10 \mathrm{mg} / \mathrm{m}^{3}$ for CO relative to another day, are shown. Also, the corresponding relative risk contrasting a day with a pollutant's level at the 95 th centile of its distribution relative to the 5 th centile is shown. It can be seen that although the magnitudes of the effects are relatively weak, they are strongly statistically significant. The coefficients of the "core" model variables are not shown, but were practically identical to those included in table 2.

The interactions of the air pollutants with season were also investigated. A significant interaction was found for $\mathrm{SO}_{2}(\mathrm{p}<0.05)$ but not for $\mathrm{BS}$ or $\mathrm{CO}$. The strongest effect of $\mathrm{SO}_{2}$ was observed during the winter; the partial regression coefficients (95\% confidence intervals) were $0.00126(0.00091,0.00161)$ and $0.00053(-0.00011,0.00117)$ for winter and summer respectively.

In Table 5, the synergistic effects of $\mathrm{SO}_{2}$ and $\mathrm{BS}$ are shown. A stronger effect of $\mathrm{SO}_{2}$ on mortality was observed when BS was at higher levels. The effect of $\mathrm{SO}_{2}$ was statistically significant during days with BS levels both below or above $100 \mu \mathrm{g} / \mathrm{m}^{3}$, but the coefficient was almost double during days with high BS levels and the interaction term was statistically significant $(p<0.01)$. The effect of BS during days with high or low $\mathrm{SO}_{2}$ levels was not, however, different to a statistically significant degree ( $p$ value for the interaction term $>0 \cdot 20$ ). But it should be noted that the number of days with $\mathrm{SO}_{2}$ levels $>100 \mu \mathrm{g} / \mathrm{m}^{3}$ in Athens during the study period was 113 and only 24 of these were in the low BS $\left(\leq 100 \mu \mathrm{g} / \mathrm{m}^{3}\right)$ category, while the number of days with BS levels $>100 \mu \mathrm{g} / \mathrm{m}^{3}$ was 492 . 
Table 5 Synergy between black smoke and $\mathrm{SO}_{2}$ levels: results from Poisson autoregressive models

\begin{tabular}{lll}
\hline Pollutant & Black smoke levels & \\
\hline & High $\left(\geq 100 \mu \mathrm{g} / \mathrm{m}^{3}\right)$ & Low $\left(<100 \mu \mathrm{g} / \mathrm{m}^{3}\right)$ \\
$\mathrm{SO}_{2}$ & $\mathrm{~b}(95 \% \mathrm{CI})$ & $\mathrm{b}(95 \% \mathrm{CI})$ \\
& $0.00143(0 \cdot 00102,0 \cdot 00184)$ & $0.00074(0 \cdot 00026,0 \cdot 00123)$ \\
\hline & $\mathrm{SO}_{2}$ levels & \\
& High $\left(\geq 100 \mu \mathrm{g} / \mathrm{m}^{3}\right)$ & Low $\left(<100 \mu \mathrm{g} / \mathrm{m}^{3}\right)$ \\
& $\mathrm{b}(95 \% \mathrm{CI})$ & $\mathrm{b}(95 \% \mathrm{CI})$ \\
Black smoke & $0.00024(-0.00029,0 \cdot 00077)$ & $0.00032(0 \cdot 00008,0 \cdot 00057)$ \\
\hline
\end{tabular}

\section{Discussion}

Recent papers from Europe ${ }^{26}$ and the USA ${ }^{20}$ indicate statistically significant, relatively weak effects of moderate or low air pollution levels on mortality. Studies from Athens for previous time periods (before 1988) have also indicated effects of moderate air pollution levels on mortality. ${ }^{8-10}$ These studies have resulted in considerable public concern since even a weak effect of air pollution is a serious public health problem due to the ubiquity of the exposure. This concern led to controversial discussions and created doubts about the safety of current air pollution standards. Furthermore, the need to evaluate collectively results published so far arose. Major points raised by scientists were focussing on methodological issues: these included adequate control of confounding (especially seasonality), synergy between pollutants, the problem of small counts, autocorrelation. $^{21-22}$ Furthermore, in Europe, it could also be seen that the studies published were few and the methodologies used differed substantially. ${ }^{23}$

The APHEA project is an attempt to analyse many similar data sets from European cities in a standardised fashion, addressing all the important methodological problems in the best possible way.

In this study, confounding was carefully addressed, autoregression was applied to control autocorrelation, and the Poisson models used allowed for overdispersion. Statistically significant effects of the air pollutants studied on mortality were found. Modelling effect modification by season indicated higher effects of $\mathrm{SO}_{2}$ during winter. In the present data, interaction among pollutants was investigated for the first time in Athens and there was evidence that the $\mathrm{SO}_{2}$ effects were greater when $\mathrm{BS}$ was at higher levels, a result which may also explain the larger $\mathrm{SO}_{2}$ effect observed during the winter when BS levels are higher. This evidence needs further investigation because it is important for taking preventative measures and protecting public health.

In the US studies, adverse effects have been primarily associated with the levels of particles (especially those with an aerodynamic diameter
$<10 \mu$ ) and not $\mathrm{SO}_{2}$ or $\mathrm{CO}$, while in our study $\mathrm{SO}_{2}$ seemed to be the most important pollutant. It must be noted that our particle measurement, BS, may not be as relevant for health outcomes as $\mathrm{PM}_{10}$ However, it is also true that the levels of $\mathrm{SO}_{2}$ in the cities involved in the US studies were lower than those observed in Athens. ${ }^{20}$

In conclusion, the analysis presented here strengthens the evidence of a causal association between ambient particle, $\mathrm{SO}_{2}$, or $\mathrm{CO}$ levels in the air and the total daily number of deaths and points once more to an important public health issue in Athens.

1 Pope CA, Schwartz J, Ransom MR. Daily mortality and Pope CA, Schwartz J, Ransom MR. Daily mortality and $\mathrm{PM}_{10}$ pollution
47:211-17.

2 Derrienic F, Richardson S, Mollie A, Lellouch J. Shortterm effects of sulphur dioxide pollution on mortality in two French cities. Int $\mathcal{F}$ Epidemiol 1989;18:186-97.

3 Wichmann HE, Mueller W, Allhoff P, et al. Health effects during a smog episode in West Germany in 1985. Environ Health Perspect 1989;79:89-99.

4 Schwartz J. Air pollution and daily mortality in Birmingham, Alabama. Am $\mathcal{F}$ Epidemiol 1993;137:1136-47.

5 Schwartz J, Dockery DW. Increased mortality in Philadelphia associated with daily air pollution concentrations. Am Rev Respir Dis 1992;145:600-4.

6 Sunyer J, Saez M, Murillo C, Castellsague J, Martinez F, Anto JM. Air pollution and emergency room admissions for chronic obstructive pulmonary disease: a 5-year study. Am 7 Epidemiol 1993;137:701-5.

7 Schwartz J, Dockery DW. Particulate air pollution and daily mortality in Steubenville, Ohio. Am 7 Epidemiol 1992;135: mortality.

8 Hatzakis A, Katsouyanni K, Kalandidi A, Day N, Trichopoulos D. Short-term effects of air pollution on mortality in Athens. Int $\mathcal{f}$ Epidemiol 1986;15:73-81.

9 Katsouyanni K, Karakatsani A, Messari I et al. Air pollution and cause specific mortality in Athens. $\mathcal{F}$ Epidemiol Community Health 1990;44:321-24.

10 Touloumi G, Pocock J, Katsouyanni K, Trichopoulos D. Short-term effects of air pollution on daily mortality in Athens: a time-series analysis. Int $\mathcal{f}$ Epidemiol 1994;23: 957-67.

11 Katsouyanni K, Pantazopoulou A, Touloumi G, et al. Evidence for interaction between air pollution and high temperature in the causation of excess mortality. Arch Envinon Health 1993;48:235-42.

12 Katsouyanni K, ed. Study designs. Commission of the European Communities, Air Pollution Epidemiology Report Series. Report number 4. Luxemburg: Office for Official Publications of the European Communities, 1993.

13 Katsouyanni K, Schwartz J, Spix C, et al. Short term effects of air pollution on health: a European approach using epidemiologic time series data: the APHEA protocol. $f$ Epidemiol Community Health 1996;50(Suppl 1):S12-S18.

14 Schwartz J, Spix C, Touloumi G, et al. Methodological issues in studies of air pollution and daily counts of deaths or hospital admissions. $\mathcal{f}$ Epidemiol Community Health 1996;50(Suppl 1):S3-S11.

5 Ministry of the Environment, Planning and Public Works. Program for air pollution control. Athens: Technical Report, 1989.

16 National Statistical Service of Greece. Results of 1991 census. Athens: National Statistical Service, 1995.

17 WHO Updating and revision of air quality guidelines for Europe: meeting of the Working Group on "Classical" Air Pollutants. Bilthoven: The Netherlands 11-14/10/1994.

18 National Observatory of Athens. Institute of Meteorology and Physics of the Atmospheric Environment. Climatological BulPhysics of the Atmospheric Environmen

19 McCullagh P, Nelder JA. Generalized linear models. 2nd ed. London: Chapman \& Hall, 1989;261.

20 Schwartz J. Air pollution and daily mortality: a review and meta-analysis. Environ Res 1994;64:35-52.

21 Utell MJ, Samet JM. Particulate air pollution and health New evidence on an old problem. Editorial, Am Rev Respir Dis 1993;147:1334-35.

22 Ostro B. The Association of Air pollution and mortality: examining the case for inference. Arch Environ Health 1993;48:336-42.

23 Katsouyanni K, Zmirou D, Spix C et al. Short term effects of air pollution on health: a European approach using epidemiologic time series data. Eur Respir F 1995;8:1030-8. 